\title{
Aloe Vera (Medicinal Plant) Research: A Scientometric Assessment of Global Publications Output during 2007-16
}

\author{
BM Gupta', KK Mueen Ahmed ${ }^{2}$, SM Dhawan ${ }^{3}$, Ritu Gupta ${ }^{4}$
}

\section{BM Gupta ${ }^{1}$, KK Mueen Ahmed ${ }^{2}$, SM Dhawan ${ }^{3}$, Ritu Gupta ${ }^{4}$}

\author{
11173 Sector 15, Panchkula 134113 \\ Haryana, INDIA. \\ ${ }^{2}$ Phcog.Net and SciBiolMed.Org, Benga- \\ luru, Karnataka, INDIA. \\ ${ }^{3} 114$ Dayanand Vihar, Delhi-110092, \\ INDIA. \\ ${ }^{4} 1 \mathrm{~K} / \mathrm{A}$ Arjun Nagar, Safdarjang Enclave, \\ New Delhi-110029, INDIA.

\section{Correspondence} \\ Ritu Gupta \\ 1K/A Arjun Nagar, Safdarjang Enclave, \\ New Delhi-110029, INDIA. \\ Phone no: 9711563995 \\ E-mail: ritu7648@gmail.com

\section{History} \\ - Submission Date: 05-10-2017; \\ - Review completed: 27-10-2017; \\ - Accepted Date: 13-11-2017
}

\section{DOI : 10.5530/pj.2018.1.1}

Article Available online http://www.phcogj.com/v10/i1

\section{Copyright}

(C) 2018 Phcog.Net. This is an openaccess article distributed under the terms of the Creative Commons Attribution 4.0 International license.

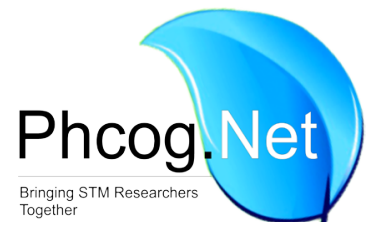

\begin{abstract}
The paper examines 1988 global publications on Aloe Vera research, as covered in Scopus database during 2007-16. The Aloe Vera research registered $3.91 \%$ growth and averaged its citation impact to 9.57 citations per paper. The top 12 most productive countries individually contributed global share $5.36 \%$ to $52.17 \%$. India accounted for the largest global publication share $(32.55 \%)$, followed by USA $(11.52 \%)$, Iran $(8.15 \%)$, China $(4.63 \%)$ etc. Together, the top 12 countries accounted for $79.18 \%$ global publications share and $84.94 \%$ global citation share during 2007-16. Seven of top 12 countries scored relative citation index above the world average i.e. 1.04: U.K. (1.82), Thailand and USA (1.63 each), Spain (1.23), Pakistan and China (1.15 each) and Italy (1.12) during 2007-16. The country share of international collaborative publications across top 12 most productive countries varied from $5.36 \%$ to $52.17 \%$, in Aloe Vera research during 2007-16. Medicine, among other subjects, accounted for the highest publications share $(40.90 \%)$, followed by pharmacology, toxicology and pharmaceutics $(35.16 \%)$, agricultural and biological sciences $(23.09 \%)$, biochemistry, genetics and molecular biology $(20.27 \%)$, chemistry $(7.90 \%)$, immunology and microbiology $(6.24 \%)$ and engineering (5.38) during 2007-16. The top 20 most productive research organizations and the authors collectively contributed $11.47 \%$ and $8.55 \%$ respectively global publication share and $12.87 \%$ and $13.82 \%$ respectively global citation share during $2007-16$. The journals medium accounted for the largest $79.08 \%$ global share with top 15 journals accounting for just $16.01 \%$ of total output that was reported in journals during 2007-16. Only 18 papers in Aloe Vera research registered 100 plus citations between 104 to 242 citations per paper, and together these papers cumulated 2656 citations, averaging to 147.55 citations per paper. These 18 highly cited papers involved the participation of 66 authors and 41 organizations and were published in 15 journals.

Key words: Aloe vera, Medicinal plant, Global research output, Scientometrics, Bibliometrics.
\end{abstract}

\section{INTRODUCTION}

Aloe Vera is a perennial, drought-resisting, succulent plant belonging to the Asphodelaceae family. The name, aloe, is derived from the Arabic " alloeh " or Hebrew "halal" meaning bitter shiny substance. It has a vast traditional role in indigenous system of medicine like Ayurveda, Siddha, Unani and homoeopathy. ${ }^{1}$ The Aloe Vera plant is a member of lily plant known as Aloe barbadensis, which is full of juice and closes like a cactus. Due to its cactus like feel, Aloe is often mistakenly called a "Desert Cacti". Aloe Barbadensis miller or Aloe Vera, a semi tropical plant is one of the 250 species of Aloe. Most commonly used for its medicinal properties, Aloe Vera or the Sanskrit name "Ghee kunwar" is a member of Lilly family. The plant has lance-shaped, sharp pointed, and jagged and edged leaves. ${ }^{2}$

Aloe is native to North Africa and Spain, now the plant is also grown in the hot dry regions of Asia, Europe and America. Aloe Vera is found as the wild herb along the coast of south India. It is under cultivation in large areas in many parts of India viz; Tamil Nadu,
Gujarat, Maharashtra etc. ${ }^{3}$ Aloes are often thought to only grow in hot and dry climates, but they actually grow in a variety of climates including desert, grassland, and coastal or even alpine locations. ${ }^{4}$

For centuries, it has been medicinally used for an array of ailments such as mild fever, wounds and burns, gastrointestinal disorders, diabetes, sexual vitality and fertility problems to cancer, immune modulation, AIDS and various skin diseases. In the pharmaceutical industry, it has been used for the manufacture of topical products such as ointments and gel preparations, as well as in the production of tablets and capsules. So, there is an urgent need to educate about the miraculous uses of Aloe Vera along with its cultivation methods for human race and popularize it for greater interest. ${ }^{5,6}$

There are more than 200 compounds found in Aloe barbadensis, about 75 of which have biological activity, Aloe Vera leaves contain a diverse array of compounds, including anthraquinones (e.g. aloe-

Cite this article: BM Gupta, Ahmed KKM, SM Dhawan, Gupta R. Aloe Vera (Medicinal Plant) Research: A Scientometric Assessment of Global Publications Output during 2007-16. Pharmacog J. 2018;10(1):1-8. 
emodin), anthrones and their glycosides (e.g. 10-(1, 5' anhydroglucosyl)aloeemodin-9-anthrone, also known as aloin A and B), chromones, carbohydrates, proteins, glycoproteins, amino acids, organic acids, lipids, sugars, vitamins and minerals. ${ }^{5,6}$

Aloe Vera has number of uses and mainly they are used as a food preservative and medicine. Commercially, aloe can be found in pills, sprays, ointments, lotions, liquids, drinks, jellies, and creams. Numerous aloe species around the world are used for conditions ranging from dermatitis to cancer. Various studies have revealed that Aloe Vera leaf possesses many pharmaceutical activities, including antimicrobial, anticancer, antioxidant, anti-diabetic, anti-ulcer, hepato-protective, immune-modulatory and many more activities. Many of the health benefits associated with Aloe Vera have been attributed to the polysaccharides contained in the gel of the leaves. ${ }^{7,8,9,10,11,12,13,14}$

\section{Literature Review}

Only few scientometric studies are available in the past, which quantitatively analyze global literature on individual medicinal plants, such as Apocynum cannabinum, ${ }^{15}$ Artemisia annua, ${ }^{16}$ Glycyrrhiza glabre, ${ }^{17}$ Phonix dactyl lifra, ${ }^{18,19}$ and Podophyllotoxin..$^{20}$

\section{OBJECTIVES}

The main objectives of this study are to study the performance of Aloe Vera research during 2007-16, based on publications output covered in Scopus database. In particular, the study focuses on the following objectives: (i) To study the growth of world research output in Aloe Vera research and its citation impact; (ii) To study the international collaboration share of top 10 most productive countries; (iii) To study the global research output by broad subject areas and the dynamics of its growth and decline; (iv) To study the trends by identifying significant keywords; (v) To study the publication productivity and citation impact of top 20 most productive organizations and authors; (vi) To study the modes of communication in research and (vii) to study the characteristics of top 18 highly cited papers.

\section{METHODOLOGY}

The study retrieved and downloaded 10-year publication data of the world in Aloe Vera research from the Scopus database (http://www.scopus.com) covering the period 2007-16. Keywords, such as "Aloe Vera" was incorporated in the search string and qualified these keywords with "keyword tag", "Article Title tag", and in addition incorporated in this search string the period '2007-16' within "date range tag". Finally, this search string was applied for searching global publication data on Aloe Vera research. The search string was subsequently refined, using analytical functions and tags in Scopus database, by "subject area tag", "country tag", "source title tag", "journal title name" and "affiliation tag", to get data/information on the distribution of publications output by subject, collaborating countries, author-wise, organization-wise and journalwise, etc. For citation data, citations to publications were also collected from date of publication till 16 December 2016.

KEY ("aloe vera") AND PUBYEAR > 2006 AND PUBYEAR < 2017

\section{ANALYSIS}

The total research output of the world in field of Aloe Vera research cumulated to 1988 publications in 10 years during 2007-16. The annual output of the world in Aloe Vera research increased from 135 in the year 2007 to 174 publications in the year 2016, registering 3.91\% growth per annum. The cumulative world output in Aloe Vera research in 5 years 2007-11 increased from 837 to 1151 publications during succeeding 5 -year period 2012-16, registering $37.51 \%$ quinquennial growth. Of
Table 1: World Output in Aloe Vera Research, 2007-16.

\begin{tabular}{cccc}
\hline $\begin{array}{c}\text { Publication } \\
\text { Period }\end{array}$ & \multicolumn{3}{c}{ World } \\
\cline { 2 - 4 } 2007 & TP & TC & CPP \\
2008 & 135 & 3105 & 23.00 \\
2009 & 146 & 3192 & 21.86 \\
2010 & 156 & 2251 & 14.43 \\
2011 & 186 & 2339 & 12.58 \\
2012 & 214 & 2758 & 12.89 \\
2013 & 241 & 1974 & 8.19 \\
2014 & 243 & 1779 & 7.32 \\
2015 & 243 & 1026 & 4.22 \\
2016 & 250 & 527 & 2.11 \\
$2007-11$ & 174 & 69 & 0.40 \\
$2012-16$ & 837 & 13645 & 16.30 \\
$2007-16$ & 1151 & 5375 & 4.67 \\
\hline
\end{tabular}

$\mathrm{TP}=$ Total Papers; $\mathrm{TC}=$ Total Citations; $\mathrm{CPP}=$ Citations Per Paper

the total global publications output, $76.46 \%$ (1520) appeared as articles, $16.45 \%(327)$ as reviews, $2.26 \%$ (45) as conference papers, $1.21 \%(24)$ as letters, $1.06 \%(21)$ as articles in press, and the rest as notes, short surveys, editorials, book chapters and erratum. The citation impact of global publications on Aloe Vera research in 10 years averaged to 9.57 citations per publication (CPP) during 2007-16; five-yearly impact averaged to 16.30 CPP for the period 2007-11, which sharply declined to 4.67 CPP in the succeeding five-year 2012-16 Table 1.

\section{Top 10 Most Productive Countries in Aloe Vera research}

The global research output in the field of Aloe Vera research had originated from as many as 92 countries in the world during 2007-16. Of the 92 countries, 60 published 1-10 papers in 10 years, 23 countries 11-50 papers, 6 countries 51-100 papers and 3 counties 162 to 647 papers. The top 12 most productive countries in Aloe Vera research contributed 45 to 647 publications each during 2007-16 Table 2. The top 12 most productive countries in Aloe Vera research accounted for 79.18\% global publication share and $84.94 \%$ citation share during 2007-16. Their five-yearly output accounted for $76.11 \%$ global publication share during 2007-11 which increased to $81.41 \%$ during succeeding 5 -year period 2012-16. Country-wise, the global publication shares of top 12 countries varied widely $2.26 \%$ to $32.55 \%$ during $2007-16$, with India accounting for the highest publication share (32.55\%), followed by USA (11.52\% share), Iran (8.15\%), and China (4.63\% share). The other 8 countries contributed their global publication share between $2.26 \%$ and $3.92 \%$ in 10 years during 2007-16. The global publication share registered an increase by $8.09 \%$ in Iran in five years period (2007-11 and $2012-16$ ), followed by $6.27 \%$ in India, $1.31 \%$ in Pakistan, $1.22 \%$ in Italy, $0.99 \%$ in Thailand, $0.81 \%$ in Spain and $0.59 \%$ in Brazil. In other top 12 countries, like the USA, UK, Nigeria, China, and South Korea, their quinquennial global share registered decline between $0.11 \%$ and $8.17 \%$ during 2007-11 to 2012-16. Seven of top 12 countries scored relative citation index above the world average of 1: U.K. (1.82), Thailand and USA (1.63 each), Spain (1.23), Pakistan and China (1.15 each) and Italy (1.12) during 2007-16. India has though emerged as the world leader in Aloe Vera research, its performance in terms of relative citation index has below the world average (0.85). 
Gupta et al. : A Scientometric Assessment of Aloe Vera (Medicinal Plant) Research

Table 2: Global Publication Share of Top 12 Most Productive Countries in Aloe Vera Research during 2007-16.

\begin{tabular}{|c|c|c|c|c|c|c|c|c|c|c|c|c|c|}
\hline \multirow[t]{2}{*}{ S.No } & \multirow{2}{*}{$\begin{array}{l}\text { Name of the } \\
\text { Country }\end{array}$} & \multicolumn{3}{|c|}{ Number of Papers } & \multicolumn{3}{|c|}{ Share of Papers } & \multirow[t]{2}{*}{ TC } & \multirow[t]{2}{*}{ CPP } & \multirow[t]{2}{*}{$\mathrm{HI}$} & \multirow[t]{2}{*}{ ICP } & \multirow[t]{2}{*}{$\%$ ICP } & \multirow[t]{2}{*}{$\mathrm{RCl}$} \\
\hline & & 2007-11 & 2012-16 & $2007-16$ & 2007-11 & 2012-16 & 2007-16 & & & & & & \\
\hline 1 & India & 242 & 405 & 647 & 28.91 & 35.19 & 32.55 & 5282 & 8.16 & 31 & 56 & 8.66 & 0.85 \\
\hline 2 & USA & 136 & 93 & 229 & 16.25 & 8.08 & 11.52 & 3567 & 15.58 & 31 & 66 & 28.82 & 1.63 \\
\hline 3 & Iran & 29 & 133 & 162 & 3.46 & 11.56 & 8.15 & 1184 & 7.31 & 19 & 13 & 8.02 & 0.76 \\
\hline 4 & China & 41 & 51 & 92 & 4.90 & 4.43 & 4.63 & 1010 & 10.98 & 18 & 20 & 21.74 & 1.15 \\
\hline 5 & Brazil & 30 & 48 & 78 & 3.58 & 4.17 & 3.92 & 625 & 8.01 & 11 & 12 & 15.38 & 0.84 \\
\hline 6 & U.K. & 43 & 26 & 69 & 5.14 & 2.26 & 3.47 & 1201 & 17.41 & 21 & 36 & 52.17 & 1.82 \\
\hline 7 & Nigeria & 35 & 21 & 56 & 4.18 & 1.82 & 2.82 & 554 & 9.89 & 12 & 3 & 5.36 & 1.03 \\
\hline 8 & Italy & 16 & 36 & 52 & 1.91 & 3.13 & 2.62 & 558 & 10.73 & 13 & 14 & 26.92 & 1.12 \\
\hline 9 & South Korea & 22 & 29 & 51 & 2.63 & 2.52 & 2.57 & 406 & 7.96 & 12 & 9 & 17.65 & 0.83 \\
\hline 10 & Thailand & 15 & 32 & 47 & 1.79 & 2.78 & 2.36 & 733 & 15.60 & 14 & 11 & 23.40 & 1.63 \\
\hline 11 & Pakistan & 13 & 33 & 46 & 1.55 & 2.87 & 2.31 & 506 & 11.00 & 11 & 11 & 23.91 & 1.15 \\
\hline \multirow[t]{4}{*}{12} & Spain & 15 & 30 & 45 & 1.79 & 2.61 & 2.26 & 530 & 11.78 & 16 & 11 & 24.44 & 1.23 \\
\hline & Total & 637 & 937 & 1574 & 76.11 & 81.41 & 79.18 & 16156 & 10.26 & 17.42 & 262 & 16.65 & 1.07 \\
\hline & World & 837 & 1151 & 1988 & 100.00 & 100.00 & 100.00 & 19020 & 9.57 & & & & \\
\hline & $\begin{array}{l}\text { Share of } 12 \\
\text { Countries in } \\
\text { World Total }\end{array}$ & 76.11 & 81.41 & 79.18 & & & & 84.94 & & & & & \\
\hline
\end{tabular}

TP=Total Papers; TC=Total Citations; $\mathrm{CPP}=$ Citations Per Paper; HI=h-index; ICP=International Collaborative Papers; RCI=Relative Citation Index

\section{International Collaboration}

The international collaborative output of top 12 most productive countries in Aloe Vera research as a national share in the country-wise output varied widely from $5.36 \%$ to $52.17 \%$, with highest share coming from U.K. (52.17\%), followed by USA (28.82\%), Italy (26.92), Spain (24.44\%), Pakistan (23.91\%), Thailand (23.40\%), China (21.74\%), South Korea (17.65\%), Brazil (15.38\%), India (8.66\%), Iran (8.02\%) and Nigeria (5.36\%) during 2007-16. Most surprisingly, India's international collaborative share in its national output in Aloe Vera research has been marginal, $8.66 \%$. This trend could be attributed to its global leadership in Aloe Vera research. Being recognized a global research hub in the field, India's need for reliance on international collaboration in research has not been significant as it is by other top 12 most productive countries in Aloe Vera research.

\section{Subject-Wise Distribution of Research Output}

The global Aloe Vera research output published during 2007-16 is distributed across seven sub-fields (as identified in Scopus database classification), with medicine accounting for the highest publications share (40.90\%), followed by pharmacology, toxicology and pharmaceutics (35.16\%), agricultural and biological sciences (23.09\%), biochemistry, genetics and molecular biology (20.27\%), chemistry (7.90\%), immunology and microbiology (6.24\%) and engineering (5.38) during 2007-16. Its activity index, which computes change in research activity in the discipline over time 2007-11 to 2012-16 (world average activity index of a given subject is taken as 100), witnessed increase in biochemistry, genetics and molecular biology (from 93.12 to 105.0), chemistry (from 95.31 to 103.41) and engineering (from 62.15 to 127.52), as against decline of research activity in medicine (from 106.34 to 95.39), pharmacology, toxicology and pharmaceutics (from 100.58 to 99.58), agricultural and biological sciences (from 108.15 to 94.07 ) and immunology and microbiology (from 113.01 to 90.54 ) from 2007-11 to 2012-16. Chemistry, among various subjects registered the highest citations impact per paper of $13.99 \mathrm{CPP}$, followed by medicine (11.79), biochemistry, genetics and molecular biology (11.33), immunology and microbiology (8.40), pharmacology, toxicology and pharmaceutics (8.29), agricultural and biological sciences (7.69) and engineering (6.48) during 2007-16 Table 3.

\section{Profile of Top 16 Most Productive Global Organizations}

The productivity of top 16 most productive global organizations In Aloe Vera Research varied from 10 to 33 publications and together they contributed $11.47 \%$ (228) publication share and $12.87 \%$ (2448) citation share during 2007-16. The scientometric profile of these top 16 organizations is presented in Table 4. Four of these organizations registered publications output greater than the group average of 14.25: Tehran University of Medical Sciences, Iran (33 papers), Islamic Azad University, Isfahan, Iran (25 papers), Indian Institute of Technology, Kharagpur, India (21 papers) and Chula long University, Thailand (18 papers) during 2007-16. Nine organizations registered impact above the group average of 10.74 citations per publication during 2007-16: Universidad de La Serena, Chile (26.67), Amity University, Noida, India (21.10), Shahrekord University of Medical Sciences, Iran (15.82), Tehran University of Medical Sciences, Iran (14.09), Chula long University, Thailand (13.72), Mazandaran University of Medical Science, Iran (12.80), Univera Inc., Seoul, South Korea (12.31), Morinaga Milk Industry Co Ltd., Japan (11.82) and National University of Singapore (11.73) during 2007-16. Six organizations registered h-index above the group average of 5.87: Universidad de La Serena, Chile (12), Tehran University of Medical Sciences, Iran (11), Chula long University, Thailand (9), National University of Singapore (7), Univera Inc., Seoul, South Korea and Morinaga Milk Industry Co Ltd., Japan (6 each) during 2007-16. Seven organizations contributed international collaborative publications share above the group average of $17.54 \%$ : National University of Singapore (81.82\%), Universidad de La Serena, Chile (50.0\%), University of Tehran, Iran and UNESP-Universidade Estadual Pasilista, Brazil (40.0\% each), Indian Institute of Technology, Kharagpur, India (19.05\%), North West University, South Africa and Mashhad University of Medical Science, Iran (18.18\% each) during 2007-16. Nine organizations registered the 
Table 3: Subject-Wise Breakup of Global Publications in Aloe Vera Research during 2007-16.

\begin{tabular}{|c|c|c|c|c|c|c|c|c|c|}
\hline \multirow[t]{2}{*}{ S.No } & \multirow[t]{2}{*}{ Subject* } & \multicolumn{3}{|c|}{ Number of Papers (TP) } & \multicolumn{2}{|c|}{ Activity Index } & \multirow{2}{*}{$\frac{\text { TC }}{2007-16}$} & \multirow{2}{*}{$\begin{array}{c}\text { CPP } \\
2007-16\end{array}$} & \multirow{2}{*}{$\begin{array}{c}\% \text { TP } \\
2007-16\end{array}$} \\
\hline & & 2007-11 & 2012-16 & 2007-16 & 2007-11 & 2012-16 & & & \\
\hline 1 & Medicine & 364 & 449 & 813 & 106.34 & 95.39 & 9588 & 11.79 & 40.90 \\
\hline 2 & Pharmacology, Toxicology and Pharmaceutics & 296 & 403 & 699 & 100.58 & 99.58 & 5797 & 8.29 & 35.16 \\
\hline 3 & Agricultural and Biological Sciences & 209 & 250 & 459 & 108.15 & 94.07 & 3531 & 7.69 & 23.09 \\
\hline 4 & Biochemistry, Genetics and Molecular Biology & 158 & 245 & 403 & 93.12 & 105.00 & 4567 & 11.33 & 20.27 \\
\hline 5 & Chemistry & 63 & 94 & 157 & 95.31 & 103.41 & 2196 & 13.99 & 7.90 \\
\hline 6 & Immunology and Microbiology & 59 & 65 & 124 & 113.01 & 90.54 & 1041 & 8.40 & 6.24 \\
\hline \multirow[t]{2}{*}{7} & Engineering & 28 & 79 & 107 & 62.15 & 127.52 & 693 & 6.48 & 5.38 \\
\hline & World Output & 837 & 1151 & 1988 & 100.00 & 100.00 & & & \\
\hline
\end{tabular}

- There is overlapping of literature covered under various subjects

TP=Total Papers; TC=Total Citations; CPP=Citations Per Paper

Table 4: Scientometric Profile of Top 20 Most Productive Global Organizations in Aloe Vera Research during 2007-16.

\begin{tabular}{|c|c|c|c|c|c|c|c|c|}
\hline S.No & Name of the Organization & TP & TC & CPP & HI & ICP & $\% I C P$ & $\mathrm{RCl}$ \\
\hline 1 & Tehran University of Medical Sciences, Iran & 33 & 465 & 14.09 & 11 & 2 & 6.06 & 1.47 \\
\hline 2 & Islamic Azad University, Isfahan, Iran & 25 & 132 & 5.28 & 5 & 3 & 12.00 & 0.55 \\
\hline 3 & Indian Institute of Technology, Kharagpur, India & 21 & 124 & 5.90 & 4 & 4 & 19.05 & 0.62 \\
\hline 4 & Chulalong University, Thailand & 18 & 247 & 13.72 & 9 & 3 & 16.67 & 1.43 \\
\hline 5 & Univera Inc., Seoul, South Korea & 13 & 160 & 12.31 & 6 & 1 & 7.69 & 1.29 \\
\hline 6 & Universidad de LaSerena, Chile & 12 & 320 & 26.67 & 12 & 6 & 50.00 & 2.79 \\
\hline 7 & Mashhad University of Medical Science, Iran & 11 & 44 & 4.00 & 4 & 2 & 18.18 & 0.42 \\
\hline 8 & Morinaga Milk Industry Co Ltd., Japan & 11 & 130 & 11.82 & 6 & 0 & 0.00 & 1.23 \\
\hline 9 & National University of Singapore & 11 & 129 & 11.73 & 7 & 9 & 81.82 & 1.23 \\
\hline 10 & Shahrekord University of Medical Sciences, Iran & 11 & 174 & 15.82 & 4 & 0 & 0.00 & 1.65 \\
\hline 11 & North West University, South Africa & 11 & 65 & 5.91 & 5 & 2 & 18.18 & 0.62 \\
\hline 12 & University of Rajasthan, Jaipur, India & 11 & 53 & 4.82 & 5 & 0 & 0.00 & 0.50 \\
\hline 13 & UNESP-Universidade Estadual Pasilista, Brazil & 10 & 29 & 2.90 & 3 & 4 & 40.00 & 0.30 \\
\hline 14 & Mazandaran University of Medical Science, Iran & 10 & 128 & 12.80 & 5 & 0 & 0.00 & 1.34 \\
\hline 15 & University of Tehran, Iran & 10 & 37 & 3.70 & 3 & 4 & 40.00 & 0.39 \\
\hline \multirow[t]{4}{*}{16} & Amity University, Noida, India & 10 & 211 & 21.10 & 5 & 0 & 0.00 & 2.20 \\
\hline & Total of 16 organizations & 228 & 2448 & 10.74 & 5.87 & 40 & 17.54 & 1.12 \\
\hline & Total of World & 1988 & 19020 & 9.57 & & & & \\
\hline & Share of top 16 organizations in World total output & 11.47 & 12.87 & & & & & \\
\hline
\end{tabular}

TP=Total Papers; TC=Total Citations; CPP=Citations Per Paper; HI=h-index; ICP=International Collaborative Papers; RCI=Relative Citation Index

relative citation index above the group average (1.12) of all organizations: Universidad de La Serena, Chile (2.79), Amity University, Noida, India (2.20), Shahrekord University of Medical Sciences, Iran (1.65), Tehran University of Medical Sciences, Iran (1.47), Chula long University, Thailand (1.43), Mazandaran University of Medical Science, Iran (1.34), Univera Inc., Seoul, South Korea (1.29), Morinaga Milk Industry Co Ltd., Japan and National University of Singapore (1.23 each) during 2007-16.

\section{Profile of Top 20 Most Productive Authors}

The research productivity in the field of Aloe Vera research of top 20 most productive authors varied from 7 to 12 publications. Together they contributed $8.55 \%$ (170) global publication share and $13.82 \%$ (2628) citation share during 2007-16. The scientometric profile of these 20 authors is presented in Table 5. Nine authors registered publications output above the group average of 8.5: A. Vega-Galvez (12 papers), M.Tanaka (11 papers), M.Miranda (10 papers), M.Abdollahi, D.Martinez-
Romero, S.Ramakrishna, M.Serrano, P.Thunyakitpisal and D.Valero (9 papers each) during 2007-16. Four authors registered impact above the group average of 15.46 citations per publication: J.Hamman (44.0), M.Miranda (28.10), A. Vega-Galvez (26.67) and M.Abdollahi (19.22) during 2007-16. Ten authors registered $\mathrm{h}$-index above the group average of 5.9 of all authors: A. Vega-Galvez (12), M.Abdollahi and D.MartinezRomero (9 each), M.Miranda and F.Gullen (8 each), S.Ramakrishna (7), J.Hamman, M.Serrano, D.Valero and M.Tanaka (6 each) during 2007-16. Four authors contributed international collaborative publications share above the group average of $12.35 \%$ of all authors: S.Ramakrishna (88.89\%), A. Vega-Galvez (50.0\%), J.Hamman (42.86\%) and M.Miranda (30.0\%) during 2007-16. Eight authors registered the relative citation index above the group average (1.62) of all authors: J.Hamman (4.60), M.Miranda (2.94), A. Vega-Galvez (2.79), M.Abdollahi (2.01), F.Gullen, S.Castillo and P.J.Zapata (1.63 each) and C.K.Lee (1.63) during 2007-16. 
Table 5: Scientometric Profile of Top 20 Most Productive Authors in Aloe Vera Research during 2007-16.

\begin{tabular}{|c|c|c|c|c|c|c|c|c|c|}
\hline S. No & Name of the Author & Affiliation of the Author & TP & TC & CPP & $\mathrm{HI}$ & ICP & $\% \mathrm{ICP}$ & $\mathrm{RCl}$ \\
\hline 1 & A. Vega-Galvez & Universidad de LaSerena, Chile & 12 & 320 & 26.67 & 12 & 6 & 50.00 & 2.79 \\
\hline 2 & M.Tanaka & Morinaga Milk Industry Co Ltd., Japan & 11 & 125 & 11.36 & 6 & 0 & 0.00 & 1.19 \\
\hline 3 & M.Miranda & Universidad de LaSerena, Chile & 10 & 281 & 28.10 & 8 & 3 & 30.00 & 2.94 \\
\hline 4 & M.Abdollahi & Tehran University of Medical Sciences, Iran & 9 & 173 & 19.22 & 9 & 0 & 0.00 & 2.01 \\
\hline 5 & D.Martinez-Romero & University of Miguel-Harnandez, Spain & 9 & 135 & 15.00 & 9 & 0 & 0.00 & 1.57 \\
\hline 6 & S.Ramakrishna & National University of Singapore & 9 & 122 & 13.56 & 7 & 8 & 88.89 & 1.42 \\
\hline 7 & M.Serrano & University of Miguel-Harnandez, Spain & 9 & 135 & 15.00 & 6 & 0 & 0.00 & 1.57 \\
\hline 8 & P.Thunyakitpisal & Chulalong University, Thailand & 9 & 93 & 10.33 & 4 & 0 & 0.00 & 1.08 \\
\hline 9 & D.Valero & University of Miguel-Harnandez, Spain & 9 & 135 & 15.00 & 6 & 0 & 0.00 & 1.57 \\
\hline 10 & S.Castillo & University of Miguel-Harnandez, Spain & 8 & 126 & 15.75 & 5 & 0 & 0.00 & 1.65 \\
\hline 11 & S.G.Do & Univera Inc., Seoul, South Korea & 8 & 42 & 5.25 & 3 & 0 & 0.00 & 0.55 \\
\hline 12 & F.Gullen & University of Miguel-Harnandez, Spain & 8 & 126 & 15.75 & 8 & 0 & 0.00 & 1.65 \\
\hline 13 & E.Misawa & Morinaga Milk Industry Co Ltd., Japan & 8 & 110 & 13.75 & 5 & 0 & 0.00 & 1.44 \\
\hline 14 & P.S.Rao & Indian Institute of Technology, Kharagpur, India & 8 & 13 & 1.63 & 3 & 0 & 0.00 & 0.17 \\
\hline 15 & P.J.Zapata & University of Miguel-Harnandez, Spain & 8 & 126 & 15.75 & 5 & 0 & 0.00 & 1.65 \\
\hline 16 & K.S.Anantharaju & East West Institute of Technology, Bangladesh & 7 & 38 & 5.43 & 4 & 0 & 0.00 & 0.57 \\
\hline 17 & M.D.Boundreau & US Food and Drug Administration, MD, USA & 7 & 73 & 10.43 & 5 & 1 & 14.29 & 1.09 \\
\hline 18 & J.Hamman & Tshwane University of Technology, South Africa & 7 & 308 & 44.00 & 6 & 3 & 42.86 & 4.60 \\
\hline 19 & C.K.Lee & Chunbuk National University, South Korea & 7 & 109 & 15.57 & 3 & 0 & 0.00 & 1.63 \\
\hline \multirow[t]{4}{*}{20} & H.Nagabhushana & Tumkar University, Tumkar, India & 7 & 38 & 5.43 & 4 & 0 & 0.00 & 0.57 \\
\hline & & Total of 20 authors & 170 & 2628 & 15.46 & 11.7 & 21 & 12.35 & 1.62 \\
\hline & & Total of World & 1988 & 19020 & 9.57 & & & & \\
\hline & & Share of top 20 authors in World total output & 8.55 & 13.82 & & & & & \\
\hline
\end{tabular}

TP=Total Papers; TC=Total Citations; CPP=Citations Per Paper; HI=h-index; ICP=International Collaborative Papers; $\mathrm{RCl}=\mathrm{Relative} \mathrm{Citation} \mathrm{Index}$

Table 6: Top 15 Most Productive Journals in Aloe Vera Research during 2007-16.

\begin{tabular}{lcccc}
\hline S.No & Name of the Journal & \multicolumn{3}{c}{ Number of Papers } \\
\cline { 3 - 5 } & & $2007-11$ & $2012-16$ & $2007-16$ \\
\hline 1 & Journal of Ethno-pharmacology & 19 & 39 & 58 \\
2 & International Journal of Pharmacy and Pharmaceutical Science & 6 & 32 & 38 \\
3 & International Journal of Pharmaceutical Science Review and Research & 10 & 19 & 29 \\
4 & International Journal of Pharma and Bio Sciences & 4 & 20 & 24 \\
5 & Research Journal of Pharmaceutical Biological and Chemical Sciences & 1 & 20 & 21 \\
6 & Phototherapy Research & 8 & 10 & 18 \\
7 & International Journal of Pharma Technology Research & 10 & 6 & 16 \\
8 & Industrial Crops and Products & 3 & 12 & 15 \\
9 & BMC Complementary and Alternative Medicine & 7 & 7 & 14 \\
10 & Carbohydrate Polymers & 3 & 11 & 14 \\
11 & Journal of Food Science and Technology & 5 & 9 & 14 \\
12 & Pharmacolgyonline & 10 & 4 & 14 \\
13 & Asian Pacific Journal of Tropical Biomedicine & 1 & 11 & 12 \\
14 & African Journal of Biotechnology & 11 & 0 & 11 \\
15 & Evidence based Complementary and Alternate Medicine & 3 & 8 & 11 \\
& Thare of top 15 journals in global journal output & 101 & 208 & 309 \\
& Total global journal output & 646 & 1206 & 1930 \\
& & 15.6 & 17.25 & 16.01 \\
\hline
\end{tabular}


Table 7: List of Significant Keywords in Literature on Global Aloe Vera Research during 2007-16.

\begin{tabular}{|c|c|c|c|c|c|c|c|c|}
\hline S.No & Keyword & Frequency & S.No & Keyword & Frequency & S.No & Keyword & Frequency \\
\hline 1 & Abdominal Discomfort & 15 & 47 & Drug Screening & 59 & 93 & Macrophage & 15 \\
\hline 2 & Abdominal Pain & 35 & 48 & Dry Skin & 22 & 94 & Magnoliphyta & 11 \\
\hline 3 & Aloe Vera Gel & 9 & 49 & Eating Disorders & 7 & 95 & Malaria & 26 \\
\hline 4 & Aloe Vera & 1559 & 50 & Echinacea & 29 & 96 & $\begin{array}{c}\text { Malignant Neoplastic } \\
\text { Disease }\end{array}$ & 16 \\
\hline 5 & Aloe Vera Extract & 719 & 51 & Ecliptic Prostrata & 18 & 97 & Medicinal Plant & 381 \\
\hline 6 & Aloe & 501 & 52 & Edema & 18 & 98 & Nanofibres & 12 \\
\hline 7 & Alternate Medicine & 109 & 53 & Erythema & 53 & 99 & Nanoparticles & 35 \\
\hline 8 & Anti-Diabetic Activity & 51 & 54 & Ethno pharmacy & 51 & 100 & Nausea & 50 \\
\hline 9 & Anti-Diabetic Agent & 51 & 55 & Fbaceae & 21 & 101 & $\begin{array}{c}\text { Non-Insulin Dependent } \\
\text { Diabetes }\end{array}$ & 64 \\
\hline 10 & Anti-Fungal Activity & 51 & 56 & Fat & 649 & 102 & Obesity & 34 \\
\hline 11 & Anti-Inflammatory Activity & 131 & 57 & Fennel & 30 & 103 & Paclitaxel & 17 \\
\hline 12 & Anti-Microbial Activity & 100 & 58 & Fenugreek & 51 & 104 & Pain & 52 \\
\hline 13 & Anti-neoplastic Activity & 70 & 59 & Fever & 49 & 105 & Pruritus & 15 \\
\hline 14 & Anti-Oxidant Activity & 166 & 60 & Flavonoids & 60 & 106 & Periodontitis & 9 \\
\hline 15 & Anti-Viral Activity & 26 & 61 & Gastrointestinal Disease & 32 & 107 & Pain & 53 \\
\hline 16 & Ageing & 14 & 62 & Genital Herpes & 9 & 108 & Psoriasis & 34 \\
\hline 17 & Aphthous Stomatitis & 9 & 63 & Gingivitis & 14 & 109 & Radiation Dermatitis & 26 \\
\hline 18 & Arthiritis & 27 & 64 & Hair Loss & 17 & 110 & Rheumatic Disease & 24 \\
\hline 19 & Asthma & 41 & 65 & Head and Neck Cancer & 13 & 111 & Radiation Injury & 18 \\
\hline 20 & Atopic Dermatitis & 23 & 66 & Headache & 44 & 112 & Rash & 30 \\
\hline 21 & Burn & 88 & 67 & Healing & 16 & 113 & Traditional Medicine & 138 \\
\hline 22 & Blood Pressure & 11 & 68 & Heart Arrhythmia & 13 & 114 & Tooth Paste & 17 \\
\hline 23 & Burning Mouth Syndrome & 7 & 69 & Heart Disease & 21 & 115 & Skin & 61 \\
\hline 24 & Burning Sensation & 24 & 70 & Heart Infarction & 10 & 116 & Skin Disease & 62 \\
\hline 25 & Constipation & 65 & 71 & $\begin{array}{c}\text { Human Immunodeficiency } \\
\text { Virus Infection }\end{array}$ & 20 & 117 & Skin Allergy & 16 \\
\hline 26 & Complementary Therapy & 50 & 72 & Hypertension & 52 & 118 & Skin Injury & 29 \\
\hline 27 & Crohn Disease & 10 & 73 & Insomnia & 12 & 119 & Taste Disorder & 9 \\
\hline 28 & Contact Dermatitis & 27 & 74 & In-Vitro Study & 449 & 120 & Ubidecarenene & 23 \\
\hline 29 & Cosmetics & 52 & 75 & Inflammation & 71 & 121 & Ulcerative Colitis & 30 \\
\hline 30 & Cosmetic Industry & 12 & 76 & Inflammatory Bowel Disease & 15 & 122 & Ulcer & 30 \\
\hline 31 & Cold Injury & 14 & 77 & Immune System & 20 & 123 & Urinary Tract Infection & 15 \\
\hline 32 & Coughing & 19 & 78 & Immunomodulation & 47 & 124 & Vomiting & 46 \\
\hline 33 & Dandruff & 16 & 79 & Immuno-stimulation & 16 & 125 & Urogenital Track Disease & 7 \\
\hline 34 & Dandelion & 16 & 80 & Immuno-suppresive Agents & 10 & 126 & Weight Gain & 21 \\
\hline 35 & Debridement & 15 & 81 & Jaundice & 26 & 127 & Weight Reduction & 30 \\
\hline 36 & Dependent Diabetic Mellitus & 64 & 82 & Keratinocyte & 13 & 128 & Wound & 48 \\
\hline 37 & Dermatitis & 31 & 83 & Kidney Disease & 17 & 129 & Wound Healing & 166 \\
\hline 38 & Dental Care & 11 & 84 & Klebsiella Pneumonia & 12 & 130 & Weakness & 15 \\
\hline 39 & Dentistry & 10 & 85 & Laxative & 38 & 131 & Xerosis & 6 \\
\hline 40 & Diabetic Mellitus & 153 & 86 & Lichen Planus & 21 & 132 & Xerostomia & 13 \\
\hline 41 & Diarrhea & 99 & 87 & Liver & 36 & 133 & Xanthorrhoeacea & 8 \\
\hline 42 & Diet Supplement & 84 & 88 & Liver Injury & 17 & & & \\
\hline 43 & Drug Activity & 61 & 89 & Liver Disease & 27 & & & \\
\hline 44 & Drug Formulation & 88 & 90 & Lactate Dehydrogenase & 17 & & & \\
\hline 45 & Drug Mechanism & 126 & 91 & Lactobacillus & 12 & & & \\
\hline 46 & Drug Safety & 103 & 92 & Lamiaceae & 29 & & & \\
\hline
\end{tabular}




\section{Medium of Research Communication}

Of the total world output on Aloe Vera research, 79.08\% (1930) appeared in journals, $16.38 \%$ (5673) in journals, $1.01 \%$ (20) in book series, $0.91 \%$ (18) in conference proceedings, $0.65 \%(13)$ as trade publications and $0.35 \%$ (7) as books, etc. during 2007-16. The top 15 most productive journals reported 11 to 58 papers each on Aloe Vera research; together they accounted for $16.01 \%$ (309 papers) of total Aloe Vera output published in journals during 2007-16. Aloe Vera research being reported increasingly in journals is gradually becoming a trend; for example, the top 15 most productive journals in five years has shown rise in their Aloe Vera output from $15.60 \%$ to $17.25 \%$ share between $2007-11$ and 2012-16. The top ranking journal is Journal of Ethno-pharmacology (with 58 papers), followed by International Journal of Pharmacy and Pharmaceutical Science (38 papers), International Journal of Pharmaceutical Science Review and Research (29 papers), International Journal of Pharma and Bio Sciences (24 papers), etc. during 2007-16 Table 6.

\section{Significant Keywords}

Around 133 significant keywords having potential to identify comparative research trends in Aloe Vera research studies including pharmacological properties and medicinal uses were discovered from the global literature on science and medicine. These keywords are listed in Table 7 in the decreasing order of the frequency of their occurrence in the literature during 2007-16.

\section{Highly Cited Papers}

A total of 18 highly cited papers were identified each cumulating at least $100+$ citations in 10 years during 2007-16. Together these 18 papers cumulated a total of 2656 citation, averaging 147.55 citations per paper, and individually cumulating 104 to 242 citations per paper in 10 years. Of the 18 highly cited papers, 9 resulted from the participation of research organizations in their role as stand-alone (non-collaborating) institutional authors and remaining 9 from two or more research organizations working in their role as collaborating partners per paper (all national collaborative). Among highly cited papers, the largest participation was seen from India (7 papers), followed by the USA and Brazil (2 papers each), Italy, Nigeria, Pakistan, South Africa and U.K. (1 paper each). These 18 highly cited papers involved the participation of 66 personal authors and 41 research organizations in total across globe. Of the 18 highly cited papers, 6 were published as articles and 12 as review papers. These 18 highly cited papers were published in 15 journals; Journal of Ethnopharmacology (4 papers) and 1 paper each in 14 other journals, namely Acta Oncology, Annals of Oncology, Asian Pacific Journal of Tropical Biomedicine, Burns, Corrosion Science, Cochrane Database of Systematic Reviews, Endocrine Metabolic and Immune Disorders, Food Chemistry, Free Radical Biology and Medicine, Indian Journal of Dermatology, Journal of Clinical Biochemistry and Nutrition, Journal of American Academy of Dermatology, Molecules and The Scientific World Journal.

\section{CONCLUSION}

Research publications data sourced from the Scopus database was analysed in this study to provide a quantitative and qualitative description of global Aloe Vera research covering 10 years period, 2007-16. The study showed that global Aloe Vera research registered 3.91\% growth and averaged its global citation impact to 9.57 citations per paper in 10 years.

Nearly $1 / 3^{\text {rd }}$ of global Aloe Vera research was mainly from India alone (32.55\% global share) whereas other 11 top ranking countries accounted for global share between $2.26 \%$ and $11.52 \%$. The top 12 most productive countries in Aloe Vera research together accounted for a high of 79.18\% global share during 2007-16. Top ranking Asian countries in Aloe Vera research dominate in quantity of research whereas western countries in the ranking list dominate more in quality of research. For example, India, Iran, China, South Korea, Thailand, and Pakistan from Asia together accounted for $52.57 \%$ global share and comparatively the USA, the U.K., Brazil, Italy and Spain for $23.79 \%$ during 2007-16. In terms of quality of research, the USA, the U.K., Brazil, Italy and Spain performed better on citation impact (averaging 13.7 citations per paper) than that of India, Iran, China, South Korea, Thailand, and Pakistan (averaging 5.79 citations per paper). National share of western countries accounting for international collaborative publications in Aloe Vera research was greater ( $15.58 \%$ to $52.17 \%$ national share) compared to that of Asian countries (8.02\% to $23.91 \%$ national share).

Medicine was the most sought after subject area of Aloe Vera research, accounting for $(40.90 \%)$ the highest publications share, followed by pharmacology, toxicology and pharmaceutics (35.16\%), agricultural and biological sciences (23.09\%), biochemistry, genetics and molecular biology (20.27\%), chemistry (7.90\%), immunology and microbiology (6.24\%) and engineering (5.38) during 2007-16. The top 20 most productive research organizations and the authors on Aloe Vera research collectively contributed $11.47 \%$ and $8.55 \%$ global publication share and $12.87 \%$ and $13.82 \%$ global citation share respectively during 2007-16.

The journals medium accounted for $79.08 \%$ global share in Aloe Vera research with top 15 most productive journals accounting for $16.01 \%$ of total publications output in journals during 2007-16. These journals are Journal of Ethno-pharmacology (58), followed by International Journal of Pharmacy and Pharmaceutical Science (38 papers), International Journal of Pharmaceutical Science Review and Research (29 papers), International Journal of Pharma and Bio Sciences (24 papers), etc. during 2007-16. Of the total global Aloe Vera research output (1988), only 18 papers registered high citations, between 104 to 242 citations per paper. These 18 highly cited papers collectively cumulated a total of 2656 citation (averaging to 147.55 citations per paper), and involved the participation of 26 authors and 27 organizations in their publication.

Conclusively, this research study reveals that Asian countries (India, Iran, China, South Korea, Thailand and Pakistan) dominate in Aloe Vera research more in terms of quantity of research, whereas western countries (the USA, the UK, Italy, Brazil and Spain) dominate instead more in terms of quality of research. For enabling Asian counties to perform better in terms of quality of research, it is desirable that the stakeholders from Asian countries may give priority to Aloe Vera research, and encourage leading academic and research organizations from the Asia for international collaboration with counterparts from western countries.

\section{REFERENCES}

1. Baby J, Justin SR. Pharmacognostic and phytochemical properties of Aloe vera linn -an overview. International Journal of Pharmaceutical Sciences Review and Research. 2010;4(2):106

2. Benefits of Aloe vera Plant, Aloe vera Juice and Aloe vera Products. Knowledge Base Script 2009;1-7. Available from: www.knowledgepublisher.com.

3. Das N, Chattopadhay RN. Commercial cultivation of Aloe. Natural Product Radiance. 2004;3:85-7.

4. Davis UC. The genus Aloe. Botanical Notes. 2009;1:1-10. Available from: http:// greenhouse.ucdavis.edu/conservatory/

5. Manvitha K, Bidya B. Aloe vera: A wonderful plant, its history, cultivational and medical uses. Journal of Pharmacognosy. 2014;2(5):85-8

6. Sharma N, Kharwal H, Abdin MZ, Varma Ajit. A review of pharmaceutical properties of Aloe vera. International Journal of Pharmaceutical Sciences Review and Research. 2014;07:31-7.

7. Bashir A, Saeed B, Talat YM, Jehan N. Comparative study of antimicrobial activities of Aloe vera extracts and antibiotics against isolates from skin infections. African Journal of Biotechnology. 2011;10(19):3835-40

8. Naveena BBK, Selva S. Antitumor activity of Aloe Vera against Ehrlich Ascites Carcinoma (EAC) in Swiss albino mice. International Journal of Pharma and Bio Sciences. 2011;2(2):400-9

9. Miladi S, Damak M. In vitro antioxidant activities of Aloe vera leaf skin extracts Journal of Society of Chim. Tunisie. 2008;10(10):110-9. 
10. Jones K. Dietary Aloe vera supplementation and glycemic control in diabetes. B5 srl. Nutracos. 2007;6-9

11. Borra SK, Lagisetty RK, Mallela GR. Anti-ulcer effect of Aloe vera in non-steroidal anti-inflammatory drug induced peptic ulcers in rats. African Journal of Pharmacy and Pharmacology. 2011;5(16):1867-71.

12. Chandan BK, Saxena AK, Shukla S, Sharma N, Gupta DK, Suri K, et al. Hepatoprotective potential of Aloe Barbadensis Mill against carbon tetrachloride induced hepatotoxicity. Ethnopharmacology. 2007;111(3):560-66.

13. Atul NC, Santhosh KC, Bhattacharjee C, Subal D, Kannan K. Studies on immunomodulatory activity of Aloe vera (Linn). International Journal of Applied Biology and Pharmaceutical Technology. 2011;2:19-22.

14. Josias HH. Composition and Applications of Aloe Vera Leaf Gel. Molecules. 2008;13(8):1599-616.
15. Ram S. A bibliometric assessment of apocynin (Apocynum cannabinum) research. Annals of Library and Information Studies. 2013;60(4):149-58.

16. Ram S. Research output on Artemisia (Artemisia annua): A bibliometric study. Annals of Library and Information Studies. 2013;58(3):237-48.

17. Ram S. A bibliometric assessment of the liquorice (Glycyrrhiza glabre) research trends. Annals of Library and Information Studies. 2015;62(1):27-32.

18. Anwar MA, Phonix-Dactyl L. A bibliometric study of the literature on Date Palm. Malaysian Journal of Library and Information Science. 2006;11(1):41-60.

19. Alhaider I, Ahmed MKK, Gupta BM. Global research output on date palm (Phonix dactyl lifra): A 12 years scientometric perspective. Scientometrics March. 2014;98(1)157-71.

20. Ram S. Research practices in herbal medicinal plant: A case study of Podophyllotoxin. Annals of Library and Information Studies. 2010;57(1):65-71.

\section{ABOUT AUTHORS}

Dr B.M.Gupta: Dr B.M.Gupta, now a retired scientist, was working as Emeritus Scientist in the NISTADS, CSIR, New Delhi from 2009 to 2013. B.M.Gupta retired from CSIR as Scientist G in July 2008. Dr B.M.Gupta has completed B.Lib Sci, Associatship in Documentation and PhD degrees. Mr Gupta is the recipient of the Fullbright Professional Fellowship in Library \& Information Science (1999) and is elected the Fellow of the Society for Information Science (2007). He was the Principal Investigator for several projects sponsored by research agencies. Dr Gupta had published more than 200 research papers mainly in the area of scientometrics in national and international journals and in national and international conferences. He has been Guest Editor of a two special issues of the serial "Scientometrics", three issues of the "DESIDOC Journal of Library \& Information Technology" and one recent special issue of "International Journal of Information Dissemination and Technology".

Dr S.M.Dhawan: Dr S.M. Dhawan is a senior consultant librarian with over 40 years professional experience in science librarianship and biliometric/scientometric studies. He superannuated in 2005 as Scientist-F and Head Library Services from National Physical Laboratory, CSIR, New Delhi. He is Ph.D in Library Science, MLIS from University of New York, USA, and M.Sc Physics from Sardar Patel University. He has worked for innovation supporting library transformation into digital era and in addition has successfully completed several biliometric/scientometric projects. Post-superannuation he continues to work on research studies in bibliometrics/scientometrics. He has authored several research papers, research reports covering several areas of library science, library management systems, and scientometrics.

Dr Ritu Gupta: Dr Ritu has completed Bachelors of Commerce from Delhi University, Bachelors and Masters in Library \& Information Science from Annamalai University and Ph.D in Library \& Information Sciences from Shri Venkateshwara University. She has contributed more than 70 papers in the area of bibliometrics \& scientometrics.

Cite this article: BM Gupta, Ahmed KKM, SM Dhawan, Gupta R. Aloe Vera (Medicinal Plant) Research: A Scientometric Assessment of Global Publications Output during 2007-16. Pharmacog J. 2018;10(1):1-8. 